\section{Questión}

Periodismo / Comunicación ISSN 1669-6581
- Av. $44 \mathrm{~N}^{\circ} 676,1^{\circ}$ piso

CP 1900 - La Plata - Argentina

www.perio.unlp.edu.ar/question

Un texto paralelo sobre el Covid-19

Darío Martínez

https://doi.org/10.24215/16696581e374

\title{
Un texto paralelo sobre el COVID-19
}

\section{A parallel text on COVID-19}

\author{
Darío G. Martínez \\ Investigador del Centro de Comunicación, Educación y Discurso (Comedi). \\ Docente de la UNLP y UNQ. \\ https://orcid.org/0000-0003-2415-8761
}

\author{
Palabras clave \\ Comunicación/Educación - Angustia - Digitalización - Memoria
}

\section{Keywords}

Communication/Education - Anguish - Digitization - Memory

\section{Escenas}

Para quienes tenemos hijos o hijas en la educación en instituciones educativas obligatorias todo empezó una semana antes que al resto de la sociedad. Todo se dio vuelta demasiado pronto. Las rutinas alteradas, los esquemas subjetivos de la organización cotidiana fueron subvertidos, la irrupción de inesperadas prácticas de cuidado. Las experiencias se trastocaron a un nivel jamás visto en todos los contextos. De la dimensión microscópica de una de ellas, la recupero como material para la escritura. No puedo esbozar conjeturas que puedan traspolarse, que sean retomadas en otras instancias. Huyo de la pretensión de convertir esto en un antecedente. Recupero la idea de texto paralelo que sugería Daniel Prieto Castillo para dar cuenta de un proceso reflexivo en el marco de una experiencia educativa. Se escribe en acto mientras la experiencia acontece y en esa escritura se problematiza la práctica. Quiero hablar de algo que se rompió y no sé cómo juntar los pedacitos. Quiero describir lo que me afecta: cómo están pasando mis hijas esta situación inédita. Por eso la primera persona y el reconocimiento de que poseo una situación de privilegio respecto de otros sectores sociales. 
La escena inicial que retomo ocurrió la tarde del viernes 13 de marzo a la salida de la escuela, del Normal 1 "Mary O. Graham" de la ciudad de La Plata. Sobre calle 51 nos aglomeramos, como los caminantes de The Walking Dead, las familias que retiramos a los niños y niñas de $1^{\circ}$ y $2^{\circ}$ grado. También se suman quienes retiran a los de $6^{\circ}$, los demás estudiantes salen por calle 50. La confianza de los tres años de jardín transcurridos entre un mismo grupo provocan vínculos entre las familias que se refuerzan en invitaciones a "jugar en la casa" de alguien y en las conversaciones circunstanciales de todos los días. El núcleo de las conversaciones de las familias de $1^{\circ} \mathrm{B}$ tenía el denominador común del corona virus. La mamá de una compañera de Amanda, mi hija pequeña, fue refractaria a los saludos con besos, como lo veníamos haciendo desde hace 3 años que nos cruzábamos a la entrada o la salida. Acto seguido, agregó que en su trabajo vinculado con la enseñanza de yoga se evitaban los contactos corporales para corregir las posturas. Con el papá de otro compañero intercambiamos pareceres sobre la cantidad de personas fallecidas. "El porcentaje de muertos es muy poco si lo comparás con el total de la población China. No sé qué pasará acá”, arriesgó en la vereda. Quizá lo dijo por el escaso manejo de información que circulaba en los medios a principios de marzo. No recuerdo si contesté algo, o si salí con algún otro tema. Sin poder verlo entonces, en esos intercambios podía intuirse algo de las posiciones en torno de la pandemia del Covid-19. Salió el grupo de $1^{\circ} \mathrm{B}$, así que nos dispusimos a retirar a nuestras hijas de la fila de la Seño E. De ahí, fuimos casi corriendo a calle 50 porque era probable que ya estuviera en la vereda el grupo de $4^{\circ} \mathrm{E}$, al que asiste Simona, mi hija mayor.

El fin de semana ya semana se hablaba de una posible suspensión de clases en todos los niveles del país. Al anochecer del domingo se confirmó la medida preanunciada. El inicio de la semana transcurrió con un escenario similar al de las medidas de paros docentes o de suspensión de clases por los problemas de infraestructura del edificio del Normal 1: ya sea por la falta de agua o la invasión bíblica de las palomas durante el 2019. (Durante el año pasado, las palomas hicieron más fuerte su presencia en el edificio escolar y se tuvieron que tomar medidas para resguardar la salud de docentes, estudiantes y personal auxiliar). Hasta ahí veníamos acostumbrados con nuestras experiencias acumuladas. La reorganización cotidiana apelaba a los repertorios de acción para sortear lo que sería unos días sin clases. El ensamblaje de afectos que construimos pacientemente todavía contaba con algunas respuestas disponibles. 
El anuncio del presidente Alberto Fernández con el decreto del aislamiento preventivo y obligatorio marcó un hito en nuestras experiencias colectivas. El 20 de marzo comenzó una situación inédita con la cuarentena.

\section{Los ensayos de continuidad}

La posibilidad de sostener algunos elementos de rutina se convertían en desafíos. Tal es así que recurrí a mis tácticas cercanas para incrementar algunas prácticas de lecturas y escritura con Amanda. Mucho de su tiempo en la escuela había transcurrido en comprender las lógicas de un nuevo dispositivo espacial: cómo llevar la mochila, preparar la botella agua para el calor en los recreos, cómo ir al baño sola con sus compañeritas, entre otras. Ella debía internalizar todas esas disposiciones en un solo un metro y veinte centímetros de altura.

Gran parte de mi formación se debe a una forma particular de comprender la comunicación y la educación. Así que fui un poco a lo tradicional y que creía que podía serme útil. Creía que podía alojarme en el método freireano. El resultado fue esta escena hilarante.

--Amanda, ¿qué palabra es la primera que se te viene a la cabeza y que más te gusta?

--Churro, papá.

La mesa de la cocina reflejó mi desconcierto de esa mañana de martes de la primera. ¿Churro como palabra generadora? ¿Justo tenía que elegir esa? ¿Con letras compuestas? Mis intentos fueron infructuosos de construir familias de palabras. Quería ensayar propuestas y ella se frustraba ante mi impaciencia. La propuesta de ilusión de continuidad con mis recursos se pulverizó en las horas matinales del primer martes de cuarentena. Al mismo tiempo, si me pienso como trabajador de las ciencias sociales en comunicación/ educación, la forma denotaba mi escasa práctica de reflexividad.

Parte de una salida del laberinto provino del grupo de WhatsApp de $1^{\circ} \mathrm{B}$. La seño E. pedía los mails de algún integrante de la familia para mandar tareas. El archivo adjunto llegó el jueves por la tarde. Mientras lo descargábamos, porque sí tenemos la suerte de tener computadoras, pensaba en la seño que mientras atendía su cotidianidad y diseñaba las líneas punteadas en Word para completar. Las actividades de esa primera semana se trataban de saber qué nombre de compañeros o compañeras tenía más letras que el propio y también encontrar palabras que empezaran con la letra de algunos de ellxs. El conjunto de palabras en imprenta mayúscula se tornaba menos opaco. La resolución de la tarea fluyó sin inconvenientes. Los tres años de nivel 
inicial hicieron el proceso de reconocimiento: "TEO es el nombre más corto" y también "ISABELLA es el más largo de todos".

Ahí había un sendero marcado por la seño E. En mi celular pasé a mayúscula los nombres de mis contactos familiares y les pedí que cuando Amanda se comunicara con ellos le manden mensaje escritos en mayúscula, y que no siempre sean audios. A ella le mostré cómo hacer para que el teclado se quede siempre en mayúsculas. En eso estamos ahora, luego de hacer la tarea que llega por mail.

Con $4^{\circ} \mathrm{E}$, algunas cosas están solucionadas. Me refiero a la lectoescritura y una relativa autonomía para comprender las tareas a realizar de Matemática, Ciencias Sociales y Ciencias Naturales. Eso nos da un respiro mientras acompañamos a $1^{\circ} \mathrm{B}$, en el otro lado de la mesa, como si estuviéramos en un espacio plurigrado de educación rural o de adultos. En cambio, con Prácticas del Lenguaje se presentan algunos obstáculos con el género fábula, conectores temporales, el pretérito perfecto y el pretérito imperfecto. También descubrimos la crueldad de los personajes de los Cuentos de la selva de Horacio Quiroga. La profe S. grabó un videíto, que editó con la aplicación de su celu, donde les contaba a su hija y su marido que estaba pensando en los mapas y la geografía. Pero agregó que, como era viernes, no mandaba tarea sino que lo haría el lunes. Finalmente, el video llegó al grupo de $4^{\circ} \mathrm{E}$ por intermedio de una mamá que también es maestra del Normal 1 y su hijo está en este año de la primaria. Entre ellas se mandaron el mensaje, y luego la mamá-maestra lo reenvió a todo el grupo. En esos grupos, tan heterogéneos y dinámicos, se yuxtaponen los sentidos mineralizados y los que aún se disputan en torno de lo educativo. Ahí se configura una metonimia de la época: decir grupo es dar por sentado que se trata de un grupo de WhatsApp.

Las semanas sucesivas mantuvieron una relativa organización con el envío de tareas por correo electrónico. Simona las iba resolviendo con el apoyo que podíamos darle, con el privilegio de poder completar algunas cosas en computadora, de entrar sin restricciones a los links enviados y de imprimir algunas hojas con las consignas escritas. A veces, le problematizaba las preguntas para cuestionar lo que intuía, desde mi perspectiva, como un potencial sentido unívoco para una pregunta. Luego se sumaron las Ilamadas grupales por Zoom. Se convirtieron en hito inicial que luego comenzó a ritualizarse. La profe $S$. diseñó la primera un jueves de la segunda semana de cuarentena. Dispuso un horario de encuentro, más tarde tuvo que adelantarlo porque en su casa necesitaban la computadora y ella era la única que podía adelantar la reunión. La profe N., de 
Prácticas del Lenguaje, se sumó en otro horario y siempre tiene a su hija en la falda mientras conversa con el grupo de $4^{\circ} \mathrm{E}$ que logró conectarse.

“¿Me escuchan?”. "Profe, si vos sos el anfitrión, tenés que admitirlos y podés silenciar a todos”. "Eh, miren el fondo que tengo. Me fui de vacaciones a la playa". "Profe se te cayó la conexión y te quedaste dura". "Esperen que se fue J., ya volvió". "Ahí, ahí, en la ventanita podemos chatear si quieren”. “¿Me escuchan? ¿Pero me escuchan?”. En menos de dos semanas, las docentes ensayaron un encuentro virtual con tecnologías que nunca habían utilizado. Esas reuniones operaron más como un verse las caras entre compañeros y compañeras dentro de un marco de interlocución limitada y la saturación de los micrófonos. Fue verse en un espejo pixelado con amigas y amigos, en rectángulos bidimensionales, que le simuló un encuentro. Digamos un paliativo.

Esto ocurría por la mañana y la tarde. Por la noche, teníamos que dormir con algunas de ellas porque extrañaban a sus amigas, se angustiaban mediante sollozos o se despertaban porque habían soñado "cosas feas".

\section{Las pistas}

En el contexto de esta situación excepcional, se presentaron algunas de las cuestiones que podíamos pretender como fundacionales para comunicación/ educación. Se reactualizó la problemática de la educación a distancia, tan en boga durante los años 60 en la etapa desarrollista de América Latina bajo los influjos de la Alianza para el Progreso (Mattelart, 1993). La tecnificación de la educación aparecía como un horizonte a conquistar por las potencias centrales, una retórica que impregnaba declaraciones biempensantes de los organismos supranacionales como la Unesco. Sin embargo, la persistente desigualdad latinoamericana estaba presente en las posibilidades de acceso al derecho humano a la educación y en las resistencias que voces politizadas querían enfrentarse a la narrativa homogeinizadora del desarrollismo (Freire, 1999).

El aislamiento social obligatorio que impuso el COVID-19 alteró, entre otras cosas, las dinámicas que la Modernidad proponía para comprender a la escuela como una formación cultural residual que otorga dominios de saber y regímenes de verdad que se producen, distribuyen y consumen en torno de la escuela (Huergo y Fernández, 2000). La mayor preocupación que se imponía en las discusiones mediatizadas en torno de la educación radicaba en cómo serían las evaluaciones 
de "los chicos" y si perderían el año. La insistencia del ministro de Educación, Nicolás Trotta, en señalar lo inédito de esta situación no parece fungir como respuesta. El sentido común de lo educativo continúa atado a la escolarización, y en particular a la acreditación de saberes mediante una situación de examen. Mantengamos eso como vigente, ¿pero quién es el referente? ¿La docente que manda la tarea por mail o los familiares que contextualizan las preguntas y respuestas? ¿Qué es lo educativo aquí? ¿La resolución de las tareas, la comprensión de lo inédito de esta experiencia histórica? ¿Todo eso y más?

Una contradicción se visibiliza. Muchas de las continuidades relacionadas con la educación pública obligatoria, por no decir la mayoría, se sostienen gracias al pago de servicios que familias y docentes realizan todos los meses a empresas privadas. En la Argentina, es muy difícil no ser cliente del Grupo Clarín o del Grupo Telefónica, quienes tienen la capacidad de ejercer presión como intentar subir las tarifas aún en contextos de pandemia. Además tienen la capacidad de financiar investigaciones globalizadas en la problematización con el campo de la educación y las tecnologías de la comunicación.

Por ello, reivindico la presencia del Estado en el diseño y gestión de políticas públicas en materia de comunicación/ educación, donde hubo períodos de nuestra historia reciente que las situaron en el plano de los derechos humanos (Morabes y Martínez, 2019). El COVID-19 también hizo notar las profundas inequidades que atraviesan al sistema educativo en un país tan extenso y vasto como la Argentina. Basta notar que la concesión que hicieron las multinacionales radicó en no cobrar los datos móviles de Internet de aquellos sitios que tuvieran la extensión edu.ar. Este gesto de responsabilidad social empresaria, matizada como gestos humanitarios del capital globalizado, colisionó con la situación de que un número importante de instituciones educativas carecían de sitios alojados en esos dominios. Varias de iniciativas virtuales se trataban de proyectos docentes que los ubicaron en los espacios sin costos de Internet -resalto lo de $\sin$ costos porque en la web nada es gratis-y que ponían a circular para sus grupos de estudiantes. La situación para las universidades fue distinta, y se beneficiaron con esta medida porque contaban con plataformas de educación a distancia bajo la extensión edu.ar y así tuvieron un punto de partida más alto.

El Ministerio de Educación de la Nación tuvo reflejos para comenzar a diseñar acciones. Algunas que se pueden mencionar en paneo rápido son: la programación en la televisión pública y en las señales Paka Paka y Encuentro; la publicación de cuadernillos de continuidad pedagógica; el 
convenio con el Foro Argentino de Radios Comunitarias (Farco) para la transmisión de programas educativos en todas las radios pertenecientes a esa organización colectiva; la presencia activa y constante de los materiales audiovisuales en redes sociales y la apelación a interactuar por allí; se simplificaron los trámites para el registro en el programa Progresar y se amplió el límite de edad para ser beneficiario.

Cuando la digitalización parecía convertirse en un imperativo, los cuadernillos y las radios llegaron analógicamente a aquellos territorios olvidados por los bytes. Ahí, el convenio con Farco, activó una tradición de comunicación/ educación que brindó una veloz respuesta en el marco de una situación excepcional. Al mismo tiempo que revalidó la importancia de los medios de comunicación comunitarios y de la necesidad de discutir nuevamente las políticas de comunicación. La comunicación/ educación en radio arrojaba la presencia federal de territorios no rentables para las compañías proveedoras de Internet.

Otro aspecto negado es la respuesta de los colectivos docentes ante la situación de cuarentena. Podrá contrargumentarse que empezaron una semana antes que el resto, pero aún así no se quedaron de brazos cruzados oteando el horizonte. Docentes y profesores ensayaron propuestas, ensayaron y erraron para volver a ensayar. Combinaron las estrategias que tenían con aquellas a las que jamás pensaron recurrir y huyeron hacia adelante. Para ser más específicos, fueron maestras y profesoras porque la docencia es una tarea feminizada en nuestro territorio nacional (Barrancos, 2010; Morgade, 1997). Sin las romantizaciones de la vocación, como trabajadoras del campo de la cultura y con las tensiones que eso implica, dieron respuesta ante el contexto. También bajo presión y sobreexplotadas, rasgo que es imposible eludir. Ese colectivo docente, heterogéneo y múltiple, adquirió mayores grados de visibilidad cuando su práctica cotidiana tuvo que ser suplida por familiares. ¿Podrán reclamar, parafraseando la consigna feminista, ahora nos ven?

Los dispositivos tecnológicos no fueron un impedimento totalizador. En parte, porque el capitalismo fue expandiendo los puntos de contacto de las generaciones con las tecnologías de la información. Solo, claro está, que direccionado por los intereses del mercado. Al mismo tiempo, sobre todo en el período 2007-2015, hubieron políticas de Estado que estuvieron destinadas a la formación docente en tecnologías y en cuestionar mínimamente el lugar del mercado (Martin, 2018; Morabes y Martínez, 2019; Rogovsky, 2019). El reto continúa siendo ensanchar otros vectores de subjetivación que no anclen exclusivamente la tecnología al lucro. Niñxs y jóvenes 
(agregaría también a docentes) ya tienen un vínculo con las tecnologías desde muy temprana edad pero en los términos que el mercado ya les prefiguró de antemano (Da Porta, 2011) con su obsolescencia programada y sus actualizaciones constantes.

Un aspecto macro se cuela en estas conjeturas. La salida argentina de la pandemia del COVID19 no podrá ser en los mismos términos que supuso la entrada. Específicamente, menciono que la reorientación estratégica tiene ser que otra diferente al neoliberalismo progresista (Fraser, 2019) que los poderes fácticos ya instalaron como coartada. Este es un artilugio que ideó una cosmovisión totalizadora de la política con varios proyectos antagónicos de reconocimiento, pero que su concepción económica es la especulación financiera. Vale un retorno sampleado e imperativo a la bandera de Simón Rodríguez: "O inventamos o erramos".

\section{El Toto}

En 1997, la Facultad de Periodismo y Comunicación Social de la Universidad Nacional de La Plata organizó un congreso importante en el edificio del Jockey Club. En el segundo piso, en el Salón de los Espejos, en una mesa de expositores escuché a Héctor Schmucler por primera vez. Al mismo tiempo, se trató de mi primer congreso como ingresante al mundo universitario. Destaco el año por lo que representa la plena vigencia del Consenso de Washington y la prepotencia neoliberal que irradiaba todos los órdenes de la vida en común. Esa escena del Toto, hablando en un salón colmado por la iluminación de las arañas de otros tiempos, retornó en mis conjeturas de escritura en el contexto signado por el COVID-19.

Schmucler, en su exposición, dialogaba con un libro publicado por Bill Gates. En ese intercambio ficticio con el magnate dueño de Microsoft, le cuestionaba los postulados que proponía como horizontes para el conjunto de la humanidad. La preponderancia de los Estados Unidos le hacía sostener a Gates en su libro reseñado que todo era posible de ser digitalizado. Schmucler hacía de la negación un acto de subversión política y decía que todo no podía ser digitalizado. Finalizó su intervención con una pregunta benjaminiana: “¿Cómo digitalizar la angustia?”. En ese cuestionamiento se alojaba un proyecto humanista, irredento, que buscaba escaparse del imperativo digitalizador del semiocapitalismo (Berardi, 2017). Al mismo tiempo, en nuestro contexto actual, resuena como una suerte de alerta a la vorágine de querer obtener conclusiones de investigación validadas por las respuestas a los Google Forms. 
¿Cómo digitalizar la angustia?, se preguntaba el Toto en el 97. Aquí, en este interrogante, es donde se intersectan los fragmentos conjeturales que describo: las escenas y las pistas. Mi texto paralelo regresa al plano de la experiencia íntima, se pliega en la intensidad de las vivencias de mis hijas. Cuando hablan con sus compañerxs les dicen que los extrañan, a las seños y las profes les repiten, Zoom mediante, lo mismo. Algo de la vida en común en las escuelas, en nuestro país, indica que todavía no ha sido conquistado por los algoritmos monetizables. También deberemos observar la memoria de la comunicación que nos dejará el mundo estallado por el COVID-19.

\section{Referencias bibliográficas}

Barrancos, D. (2010). Mujeres en la sociedad argentina: una historia de cinco siglos. Buenos Aires: Sudamericana.

Berardi, F. B. (2017). Fenomenología del fin. Sensibilidad y mutación conectiva. Ciudad Autónoma de Buenos Aires: Caja Negra.

Da Porta, E. (2011). Procesos de mediatización y constitución de subjetividades. El caso de los jóvenes de Km 8 (tesis doctoral). La Plata: Facultad de Periodismo y Comunicación Social- UNLP.

Fraser, N. (2019). ¡Contrahegemonía ya! Ciudad Autónoma de Buenos Aires: Siglo XXI Editores. Freire, P. (1999). Pedagogía del oprimido. México: Siglo XXI.

Huergo, J., y Fernández, M. B. (2000). Cultura escolar, cultura mediática / Intersecciones. Bogotá: Universidad Pedagógica Nacional.

Martin, M. V. (2018). Políticas públicas de formación del profesorado en TIC (tesis doctoral). La Plata: Facultad de Periodismo y Comunicación Social-UNLP.

Mattelart, A. (1993). La comunicación-mundo. Historia de las ideas y de las estrategias. Buenos Aires: Fundesco.

Morabes, P., y Martínez, D. (2019). Miradas en articulación. Trayectorias y territorios en comunicación/ educación. La Plata: Edulp.

Morgade, G. (1997). Mujeres en la educación, género y docencia en la Argentina (1870-1930). Buenos Aires: Miño y Dávila.

Rogovsky, C. (2019). Subjetividades y dispositivos de comunicación/educación en las políticas públicas de formación docente (tesis doctoral). La Plata: Facultad de Periodismo y Comunicación Social-UNLP. 